\title{
Biomimetic Ceramic Composite: Characterization, Cell Response, and In Vivo Biocompatibility
}

\author{
Hung-Yang Lin ${ }^{1}$, Yi-Jung Lu ${ }^{2,+}$, Hsin-Hua Chou ${ }^{3,4}{ }^{\oplus}$, Keng-Liang Ou ${ }^{5,6,7,8,9,10} \mathbb{1}$, Bai-Hung Huang ${ }^{5,11}$, \\ Wen-Chien Lan ${ }^{6}$, Takashi Saito ${ }^{8}$ (D), Yung-Chieh Cho ${ }^{5,12}$, Yu-Hsin Ou ${ }^{13,14}$, Tzu-Sen Yang ${ }^{15, *}$ and Pei-Wen Peng ${ }^{16, *}$
}

check for updates

Citation: Lin, H.-Y.; Lu, Y.-J.; Chou, H.-H.; Ou, K.-L.; Huang, B.-H.; Lan, W.-C.; Saito, T.; Cho, Y.-C.; Ou, Y.-H.; Yang, T.-S.; et al. Biomimetic Ceramic Composite: Characterization, Cell Response, and In Vivo Biocompatibility. Materials 2021, 14, 7374. https:// doi.org/10.3390/ma14237374

Academic Editors: Tobias Tauböck and Matej Par

Received: 15 October 2021

Accepted: 29 November 2021

Published: 1 December 2021

Publisher's Note: MDPI stays neutral with regard to jurisdictional claims in published maps and institutional affiliations.

Copyright: (C) 2021 by the authors. Licensee MDPI, Basel, Switzerland. This article is an open access article distributed under the terms and conditions of the Creative Commons Attribution (CC BY) license (https:/ / creativecommons.org/licenses/by/ $4.0 /)$.
1 Department of Dentistry, Fu Jen Catholic University Hospital, Fu Jen Catholic University, New Taipei City 242, Taiwan; a00207@mail.fjuh.fju.edu.tw

2 Division of Family and Operative Dentistry, Department of Dentistry, Taipei Medical University Hospital, Taipei 110, Taiwan; yi_jung2002@yahoo.com.tw

3 School of Oral Hygiene, College of Oral Medicine, Taipei Medical University, Taipei 110, Taiwan; hhchou@tmu.edu.tw

4 Dental Department of Wan-Fang Hospital, Taipei Medical University, Taipei 116, Taiwan

5 Biomedical Technology R \& D Center, China Medical University Hospital, Taichung 404, Taiwan; klou@tmu.edu.tw (K.-L.O.); u109312001@cmu.edu.tw (B.-H.H.); D204106003@tmu.edu.tw (Y.-C.C.)

6 Department of Oral Hygiene Care, Ching Kuo Institute of Management and Health, Keelung 203, Taiwan; jameslan@ems.cku.edu.tw

7 Department of Dentistry, Taipei Medical University-Shuang Ho Hospital, New Taipei City 235, Taiwan

8 Division of Clinical Cariology and Endodontology, Department of Oral Rehabilitation, School of Dentistry, Health Sciences University of Hokkaido, Hokkaido 061-0293, Japan; t-saito@hoku-iryo-u.ac.jp

9 3D Global Biotech Inc., New Taipei City 221, Taiwan

10 Taiwan Society of Blood Biomaterials, New Taipei City 221, Taiwan

11 Graduate Institute of Dental Science, College of Dentistry, China Medical University, Taichung 404, Taiwan

12 School of Dentistry, College of Oral Medicine, Taipei Medical University, Taipei 110, Taiwan

13 Excelsior School, Arcadia, CA 91007, USA; jennifer30526@gmail.com

14 Research Center for Biomedical Devices and Prototyping Production, Taipei Medical University, Taipei 110, Taiwan

15 Graduate Institute of Biomedical Optomechatronics, College of Biomedical Engineering, Taipei Medical University, Taipei 110, Taiwan

16 School of Dental Technology, College of Oral Medicine, Taipei Medical University, Taipei 110, Taiwan

* Correspondence: tsyang@tmu.edu.tw (T.-S.Y.); apon@tmu.edu.tw (P.-W.P.)

+ Co-first author: Yi-Jung Lu.

Abstract: The present study aimed to synthesize biphasic calcium phosphate ceramics (CaPs) composed of $\beta$-tricalcium phosphate ( $\beta$-TCP) and hydroxyapatite (HAp) from the propagated Scleractinian coral and dicalcium phosphate anhydrous using a solid-state reaction followed by heat treatment at a temperature of $1100{ }^{\circ} \mathrm{C}$ for $1 \mathrm{~h}$ to 7 days. The as-prepared coral and coral-derived biphasic CaPs samples were characterized through scanning electron microscopy, X-ray diffractometry, Fourier transform infrared spectroscopy, and Raman spectroscopy. The cell response of the biphasic CaPs was evaluated by in vitro cytotoxicity assessment using mouse fibroblast (L929) cells. The bilateral femoral defect rabbit model was used to assess the early local reaction of the coral-derived biphasic CaPs bone graft on tissue. The results confirmed that the co-existence of $\beta$-TCP and HAp was formed at $1100{ }^{\circ} \mathrm{C}$ for $1 \mathrm{~h}$. The ratio of HA/ $\beta$-TCP increased as the heat-treatment time increased. The coral-derived biphasic CaPs comprising 61\% HAp and 39\% $\beta$-TCP (defined as HT-3) were not cytotoxic. Furthermore, no significant differences in local tissue reaction were observed between the HT-3 sample and autogenous bone. Therefore, the synthesized coral-derived biphasic CaPs is a candidate for bone grafting due to its good biocompatibility.

Keywords: bioactive materials; bioceramics; biocompatibility; composites; calcium phosphate 


\section{Introduction}

Coral exoskeletons possess unique interconnected porous architecture including tubular cavities ranging from 100 to $250 \mathrm{~mm}$ in length, similar to human bones and teeth, and have consequently attracted attention in orthopedics and maxillofacial surgery [1,2]. The presence of macropores greater than 150-500 $\mu \mathrm{m}$ in diameter facilitates nutrient diffusion, enables osteogenesis, and enhances bone formation [3]. Coral exoskeletons are crystals composed of calcium carbonate in the form of aragonite or calcite; their resorption rate as a bone growth rate is too fast to allow sufficient bone ingrowth, which limits clinical applications [4-6].

Hydroxyapatite $\left(\mathrm{HAp}, \mathrm{Ca}_{10}(\mathrm{PO} 4)_{6}(\mathrm{OH})_{2}\right)$ is more similar to bone and teeth and shows lower solubility than calcium carbonates in the body fluids [7-9]. Therefore, biomimetic synthesis methods have been explored to include HAp and other $\mathrm{CaP}$ with the calcium carbonate microstructure with the interconnected macroporosity [10-14]. Both in vitro and in vivo studies have demonstrated that the bioceramics from these biogenic sources have dual functions of osteoconduction and osteoinduction $[13,14]$.

The co-existence of HAp and $\beta$-tricalcium phosphate $\left(\beta-\mathrm{TCP}, \mathrm{Ca}_{3}\left(\mathrm{PO}_{4}\right)_{2}\right)$ was often observed under the routes to synthesize the pure HAp or $\beta$-TCP [15]. $\beta$-TCP has a comparable chemical composition to HAp; however, it is considered resorbable in vivo due to its faster release of $\mathrm{Ca}^{2+}$ and $\mathrm{PO}_{4}{ }^{3-}$ ions when exposed to physiological fluids [16,17]. As bone graft substitutes, mixtures of the stable HAp with $\mathrm{Ca} / \mathrm{P}$ ratio of 1.67 and the soluble $\beta$-TCP with $\mathrm{Ca} / \mathrm{P}$ ratio of 1.5 have demonstrated higher efficacy for degradation rate to match the new bone formation rate when compared with single-phase HAP or $\beta$-TCP [18-20].

Hydrothermal conversion is the preferred method for the production of coral-derived HAp. However, this synthetic process is inappropriate for commercial manufacturing because this process is slow, has complicated $\mathrm{pH}$ adjustments, and limited $\beta$-TCP batch size [21-23]. Under the solid-state reaction route, a homogeneous mixture of calcium and phosphate precursors can be mixed in water at room temperature to synthesize a biphasic $\mathrm{CP}$ with a controlled ratio of HAp to $\beta$-TCP using various heat-treatment temperatures and durations [21,24]. Highly crystalline and biphasic CaPs synthesized were suitable for mass production, high reproducibility, and low processing cost [25].

The present study aimed to synthesize highly crystalline biphasic CaPs from propagated Scleractinian coral [26] and dicalcium phosphate anhydrous (DCPA, $\left.\mathrm{CaHPO}_{4}\right)$ using a solid-state reaction followed by heat treatment. The influence was investigated of the heattreated durations on the formation of the crystalline $\mathrm{CaPs}$ and their respective cytotoxicity properties. The rabbit bone defect model was used to assess the potential of coral-derived CPs as bone grafting.

\section{Materials and Methods}

\subsection{As-Prepared Coral Granules}

DCPA was used as a phosphate precursor. The propagated Scleractinian coral was purchased (Popeye Marine Biotechnology Limited, New Taipei City, Taiwan). Organic substances were removed using a self-developed cleaning process, and the coral was manually crushed and sieved using a $595 \mu \mathrm{m}$-mesh sieve. These deproteinized coral granules were washed thoroughly using the demineralized water, neutralized with phosphate-buffered saline (PBS), and sterilized in an autoclave. A commercial coral calcium powder, hereafter denoted as SMP-44 (Biomed herbal, Taichung, Taiwan), was used for comparison.

\subsection{Coral-Derived Biphasic CaPs}

The as-prepared coral granules and DCPA with the Ca to $\mathrm{P}$ (designated as $\mathrm{Ca} / \mathrm{P}$ ) molar ratio of 1.50 were mixed in demineralized water and homogenized in a brushless stirrer at a rotation speed of $450 \mathrm{rpm}$ for $4 \mathrm{~h}$. After filtering and drying, the mixture was heat-treated at $1100{ }^{\circ} \mathrm{C}$ in the high-temperature furnace (JH-4, Kingtech Sciencetific, Taipei, Taiwan) for a specified duration. The samples herein were referred to as HT-0.1, HT-3, and HT-7 when the heat treatment was for 1 h, 3 days, and 7 days. 


\subsection{Surface and Microstructure Analysis}

Crystallinity analysis and phase identification of the heat-treated samples were performed using X-ray diffractometry (XRD; Rigaku 2200, Tokyo, Japan) operated with $\mathrm{Cu}$ Karadiation operated at $50 \mathrm{kV}$ and $250 \mathrm{~mA}$. Crystalline phases were identified by comparing the database from the Joint Committee on Powder Diffraction Standards (JCPDS) [27]. The mass fraction was semi-quantified using the area of the peaks from $\beta$-TCP (0210) and the sum of the area of the peaks from HA (211) and $\beta$-TCP (0210). The chemical bonding information of the samples was characterized via Fourier-transform infrared spectroscopy (FTIR; Perkin-Elmer Spectrum 100, Shelton, CT, USA) with a spectral resolution of $4 \mathrm{~cm}^{-1}$. Surface morphology of the samples was examined using scanning electron microscopy (SEM; JEOL-6500F, Tokyo, Japan) using an accelerating voltage of $20 \mathrm{kV}$ [28,29]. Raman spectra were recorded at room temperature using Raman and a scanning near-field, optical microscope equipped with a $633 \mathrm{~nm}$ excitation laser source (Horiba HR800, Protrustech Co., Ltd., Taipei, Taiwan) [24,30].

\subsection{In Vitro Cytotoxicity Evaluation}

The mouse fibroblast cell line (L929 RM60091, Bioresource Collection, and Research Center, Hsinchu, Taiwan) was adopted in this experiment according to ISO 10993-5 specification [31]. The cells were seeded in culture dishes at a density of $5 \times 10^{4}$ cells per $100 \mu \mathrm{L}$ in $\alpha$-Minimum Essential Medium (MEM; Level Biotechnology, New Taipei City, Taiwan). Cells from passage 2 were harvested at $80 \%$ confluence and used for further 3-[4,5-dimethylthiazol-2-yl]-2,5-diphenyltetrazolim bromide (MTT) assay. The extracts of the investigated samples were placed in an orbital shaker maintained at $37^{\circ} \mathrm{C}$ for $24 \mathrm{~h}$ with a mass to volume extraction ratio of $0.2 \mathrm{~g} / \mathrm{mL}$, which was followed by filtering and sealing in sterile bottles. L929 cells at a density of $1 \times 10^{4}$ cells/well were cultured in MEM and seeded on the 24-well culture plates. After obtaining a confluent monolayer, the medium was replaced by $0.1 \mathrm{~mL}$ sample extracts and incubated for $24 \mathrm{~h}$ at $37^{\circ} \mathrm{C}$ in an atmosphere of $5 \% \mathrm{CO}_{2}(n=3)$. Subsequently, a $10 \mu \mathrm{L}$ MTT assay kit (R\&D system, Minneapolis, MN, USA) was added to each well and incubated for $2 \mathrm{~h}$. The optical density (OD) value of each plate was read at $570 \mathrm{~nm}$ using a microplate reader (ELx800, BioTek, Winooski, VT, USA). The cell viability is expressed as shown in Equation (1):

$$
\text { Viability rate }(\%)=\frac{\mathrm{OD}_{\mathrm{HT}}-\mathrm{OD}_{\mathrm{b}}}{\mathrm{OD}_{\mathrm{nc}}-\mathrm{OD}_{\mathrm{b}}} \times 100 \%
$$

where HT represents the measured OD of the samples, and nc and $\mathrm{b}$ represent the measured ODs of the negative control (NC) and the blank. The culture medium with $10 \%(v / v)$ dimethyl sulfoxide (DMSO) and an extract from high-density polyethylene were used as positive control (PC) and NC [32].

For qualitative evaluation, L929 cells at a density of $5 \times 10^{4}$ cells/well were seeded on the 24-well culture plates and incubated for $24 \mathrm{~h}$ at $37^{\circ} \mathrm{C}$ in an atmosphere of $5 \% \mathrm{CO}_{2}$. The original culture medium was replaced by $0.5 \mathrm{~mL}$ sample extracts and incubated for $24 \mathrm{~h}$ at $37^{\circ} \mathrm{C}$ in an atmosphere of $5 \% \mathrm{CO}_{2}(n=3)$. Then, the cells were stained with the neutral red solution (Merck Taiwan, Taipei, Taiwan). Changes in cell morphology, cell lysis, and membrane integrity were observed using the inverted fluorescence microscope (FV1000/IX81, Olympus, Tokyo, Japan) under different magnifications.

\subsection{A Pilot Study of the Rabbit Model for In Vivo Biocompatibility Assessment}

A pilot study was carried out at Master Laboratory Co., Ltd. (Hsinchu, Taiwan) according to the standard of ISO 10993-6:2016 "Biological evaluation of medical devicesPart 6: Tests for local effects after implantation". Five New Zealand white rabbits weighing $2.8-3 \mathrm{~kg}$ (Livestock Research Institute, Tainan, Taiwan) were used to assess in vivo local tissue reaction using a bone defect model at the distal femur where autogenous bone was used for comparison. Before implantation, rabbits were sedated by intramuscular injection of tiletamine-zolazepam (10 mg/kg, Virbac Taiwan, Taipei, Taiwan) and xylazine 
hydrochloride (10 mg/kg, Bayer Taiwan, Taipei, Taiwan); then, they were anesthetized with isoflurane under aseptic conditions. Bone defects were created with a diameter of $4 \mathrm{~mm}$ and depth of $5 \mathrm{~mm}$ in the bilateral condyle of the femur using a motorized drill (Frios Unit S, Dentsply Sirona Taiwan, New Taipei City, Figure 1a). The bone graft sample was implanted into the defect site on the right femur, and the autogenous bone was implanted into the left femur (Figure 1 b) by a well-trained veterinary. The rabbit was euthanized with carbon dioxide 4 weeks post-operatively. Bone blocks were collected from the adjacent and bottom regions of original bone defects for histological analysis. The bone blocks were fixed in 10\% neutral-buffered formalin, dehydrated using ethanol, embedded in methyl methacrylate (MMA), sectioned into 4 to $5 \mu \mathrm{m}$-thick slices, stained with hematoxylin and eosin (H\&E), and observed via using the Aperio CS pathology scanner (Leica Biosystems, Buffalo Grove, IL, USA).

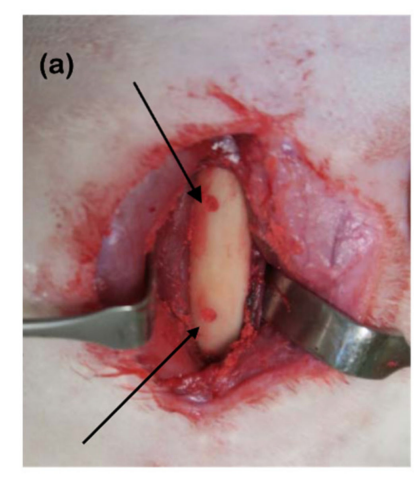

(b)

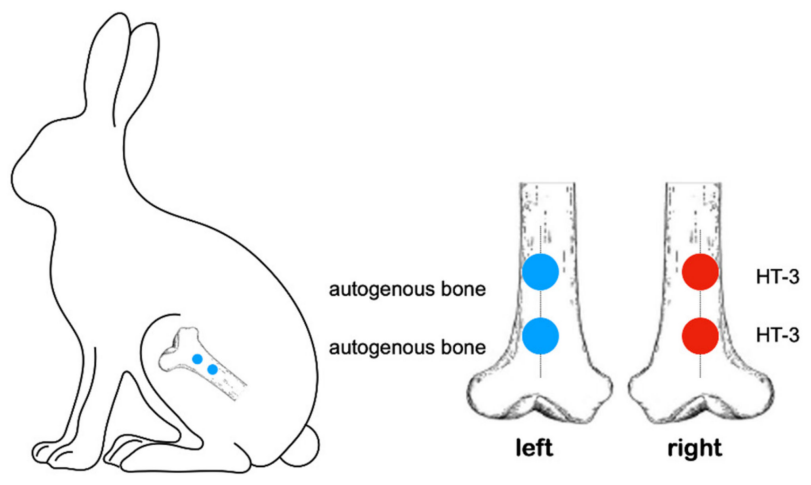

Figure 1. (a) Surgical model and (b) a schematic implantation design in the right distal femur of rabbit.

\subsection{Statistical Analysis}

The SPSS statistic software (Version 19.0., SPSS Inc., Chicago, IL, USA) was used to analyze the experimental data. The difference between groups was determined by one-way analysis of variance followed by Tukey's HSD post hoc test. A $p$ value of less than 0.05 was considered as statistically significant.

\section{Results}

\subsection{Characterizations of the Propagated Coral Granules}

The SEM image in Figure 2a reveals the as-prepared coral granules with interconnected pore sizes of 100 to $250 \mu \mathrm{m}$. A polycrystalline and fibrous morphology was observed at the highly magnified image; as shown in Figure $2 b-d$, the SMP-44 sample of commercial coral calcium powder did not have the interconnected pores.

Figure 3a shows that the as-prepared coral exhibited a fully crystalline, single phase of aragonite (JCPDS 01-076-0606), which is similar to the literature [4]. The diffractogram of the SMP-44 sample shown in Figure 3b showed crystalline peaks corresponding to $(\mathrm{Ca}, \mathrm{Mg}) \mathrm{CO}_{3}$, but the peaks slightly shifted to larger diffraction angles (JCPDS 00-005-0622).

FTIR spectra revealed that the as-prepared coral exhibited the characteristic bands for aragonite at 712 (in-plane bending mode, $v 4$ ), 854 (out of plane bending mode, $v 2$ ), 1082 (symmetric stretching mode $v 1$ ), and 1472 (asymmetric stretching, $v 3$ ) $\mathrm{cm}^{-1}$, as shown in Figure 4a. The Raman spectroscopy confirmed the phases present, as shown in Figure $4 \mathrm{~b}$. The characteristic Raman symmetric stretching band $(v 1)$ at $1087.6 \mathrm{~cm}^{-1}$ and the in-plane bending mode $(v 4)$ at $705.8 \mathrm{~cm}^{-1}$ of the Raman spectra also indicate that the as-prepared coral granules were aragonite. 

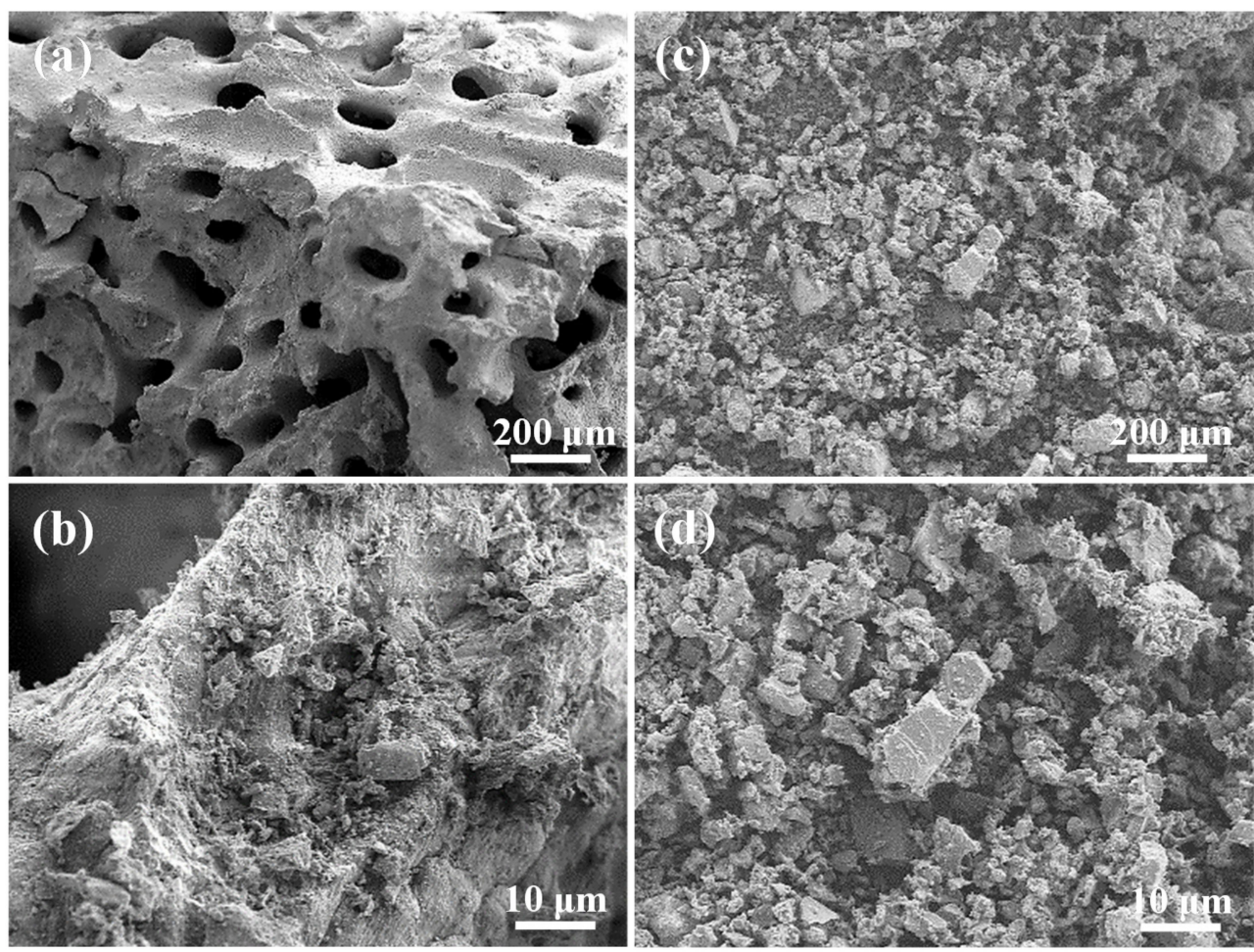

Figure 2. Comparisons between as-prepared coral and commercial coral calcium powder samples. (a) SEM image of the as-prepared coral, (b) a higher magnification SEM image of the as-prepared coral, (c) SEM image of the commercial coral calcium sample, and (d) a higher magnification SEM image of the commercial coral calcium sample.

\subsection{Effects of Heat-Treated Duration on the Formation of Biphasic CaPs}

Figure 5 shows the XRD patterns of the samples prepared by the heat treatment of as-prepared coral and DCPA at various durations. The diffraction spectra of all heattreated samples were similar. A complete decomposition of $\mathrm{CaCO}_{3}$ took place; these diffraction peaks were absent after heat treatment. Only $\beta$-TCP (JCPDS 00-009-0169) and HAp (JCPDS 01-084-1998) phases were observed for all heat-treated samples. The diffraction intensity of the peaks corresponding to $\beta$-TCP decreased with longer heattreated time. Table 1 presents the results of semi-quantification of the crystalline phases in biphasic CaPs, showing that longer heat treatment created more HAp.

Table 1. Relative phase content (\%) in biphasic CaP synthesized for varying durations.

\begin{tabular}{cccc}
\hline Phase & HT-0.1 & HT-3 & HT-7 \\
\hline HAp & 39.8 & 61.0 & 62.6 \\
$\beta$-TCP & 60.2 & 39.0 & 37.4 \\
\hline
\end{tabular}

Figure 6 shows the effect of heat treatment duration on the FTIR spectra. The spectra of all heat-treated samples were similar, having the hydroxyl $\left(\mathrm{OH}^{-}\right)$and phosphate $\left(\mathrm{PO}_{4}^{3-}\right)$ groups characteristic of CaPs. The sharp peak at $3643 \mathrm{~cm}^{-1}$, belonging to the stretching vibration motion of the $\mathrm{OH}^{-}$groups, was observed for all heat-treated samples. The bond regions of $\mathrm{PO}_{4}^{3-}$ groups at $611-540 \mathrm{~cm}^{-1}$ and $1139-944 \mathrm{~cm}^{-1}$ were also observed in all heattreated samples, as were the asymmetrical stretching bands $v 3\left(1139 \mathrm{~cm}^{-1}\right)$, the symmetric stretching bands $v 1\left(944 \mathrm{~cm}^{-1}\right)$, and the bending bands $v 4\left(611,586\right.$ and $\left.543 \mathrm{~cm}^{-1}\right)$, which were related to $\mathrm{PO}_{4}^{3-}$ groups of $\beta$-TCP $[13,29]$. All samples also presented the asymmetrical P-O stretching mode $(v 3)$ at $1086 \mathrm{~cm}^{-1}$, the asymmetrical bending modes $(v 4)$ at 600 and $568 \mathrm{~cm}^{-1}$, and the symmetric stretching modes at $962(v 1)$ and $474(v 2) \mathrm{cm}^{-1}$, which are distinguishable peaks in the $\mathrm{PO}_{4}^{3-}$ groups of crystalline HAp [18]. Two peaks were 
exhibited at $3544 \mathrm{~cm}^{-1}$ and $3571 \mathrm{~cm}^{-1}$ that represented the stretching vibrations of the $\mathrm{OH}^{-}$groups in crystalline HAp. A trace of the symmetric stretching vibration of the $\mathrm{HPO}_{4}^{2-}$ groups at $877 \mathrm{~cm}^{-1}$ appeared in all heat-treated samples.
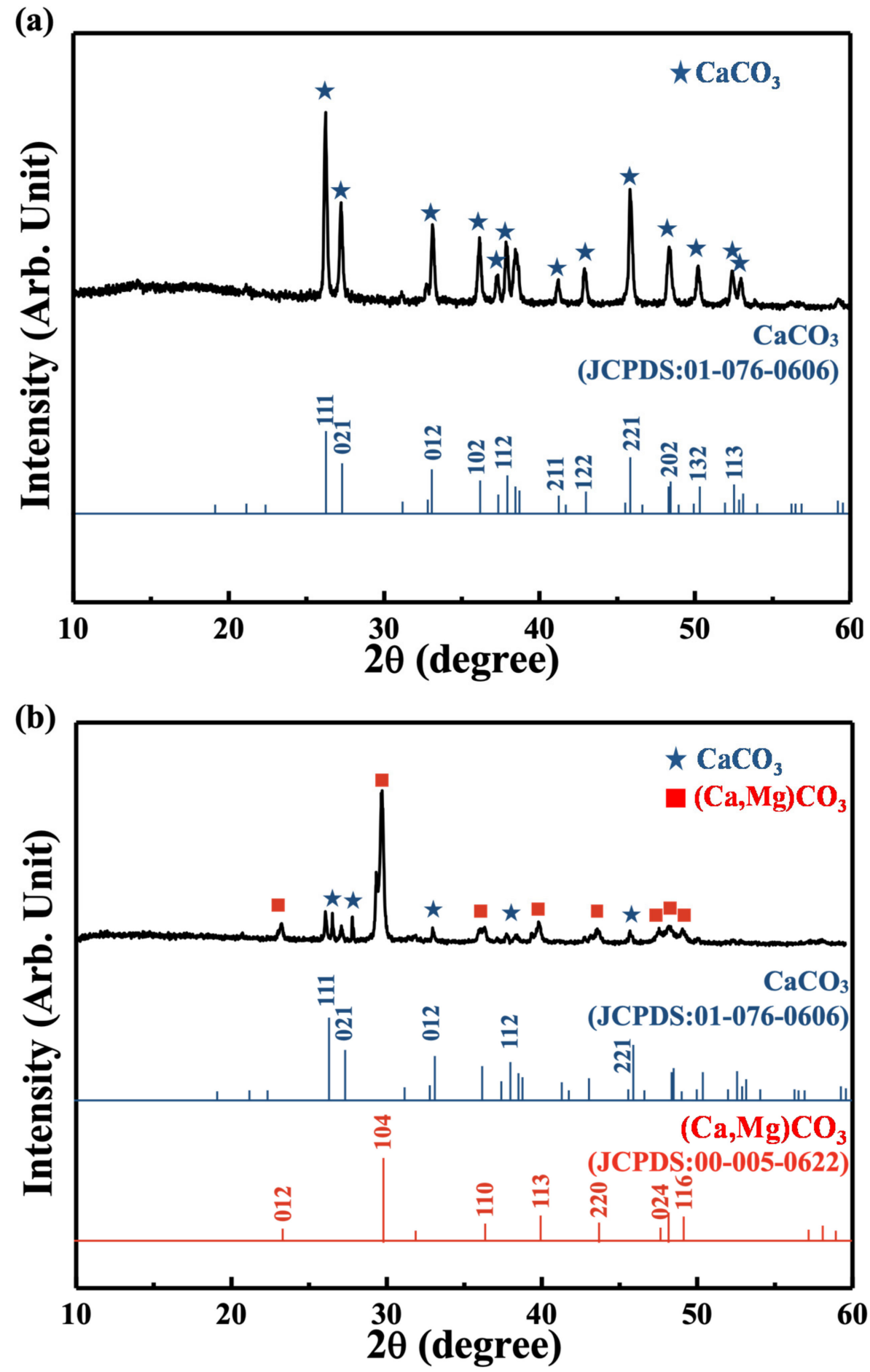

Figure 3. XRD pattern of (a) the as-prepared coral and (b) the commercial coral calcium sample. 

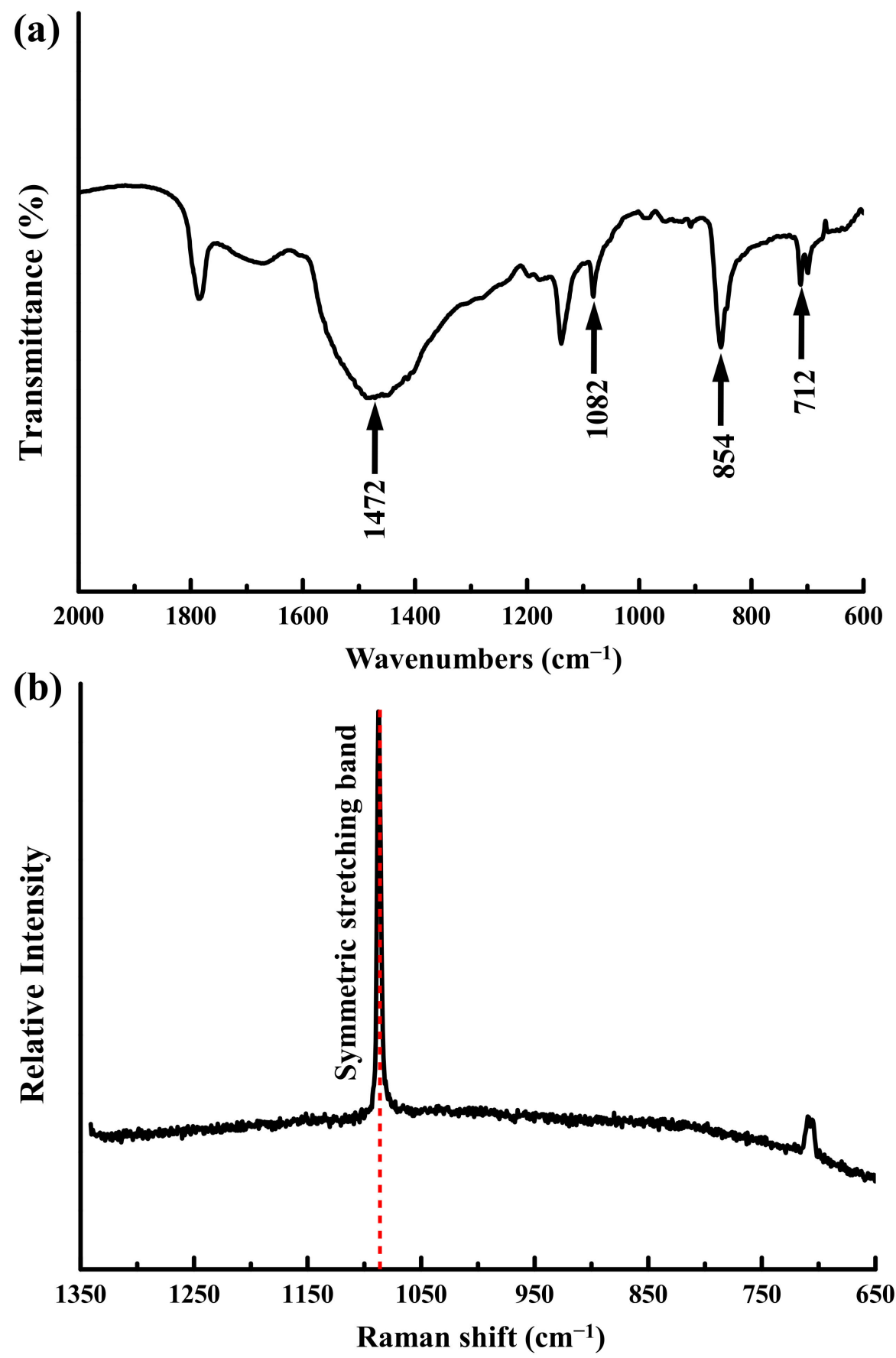

Figure 4. (a) FTIR and (b) Raman spectra of the as-prepared coral sample. 


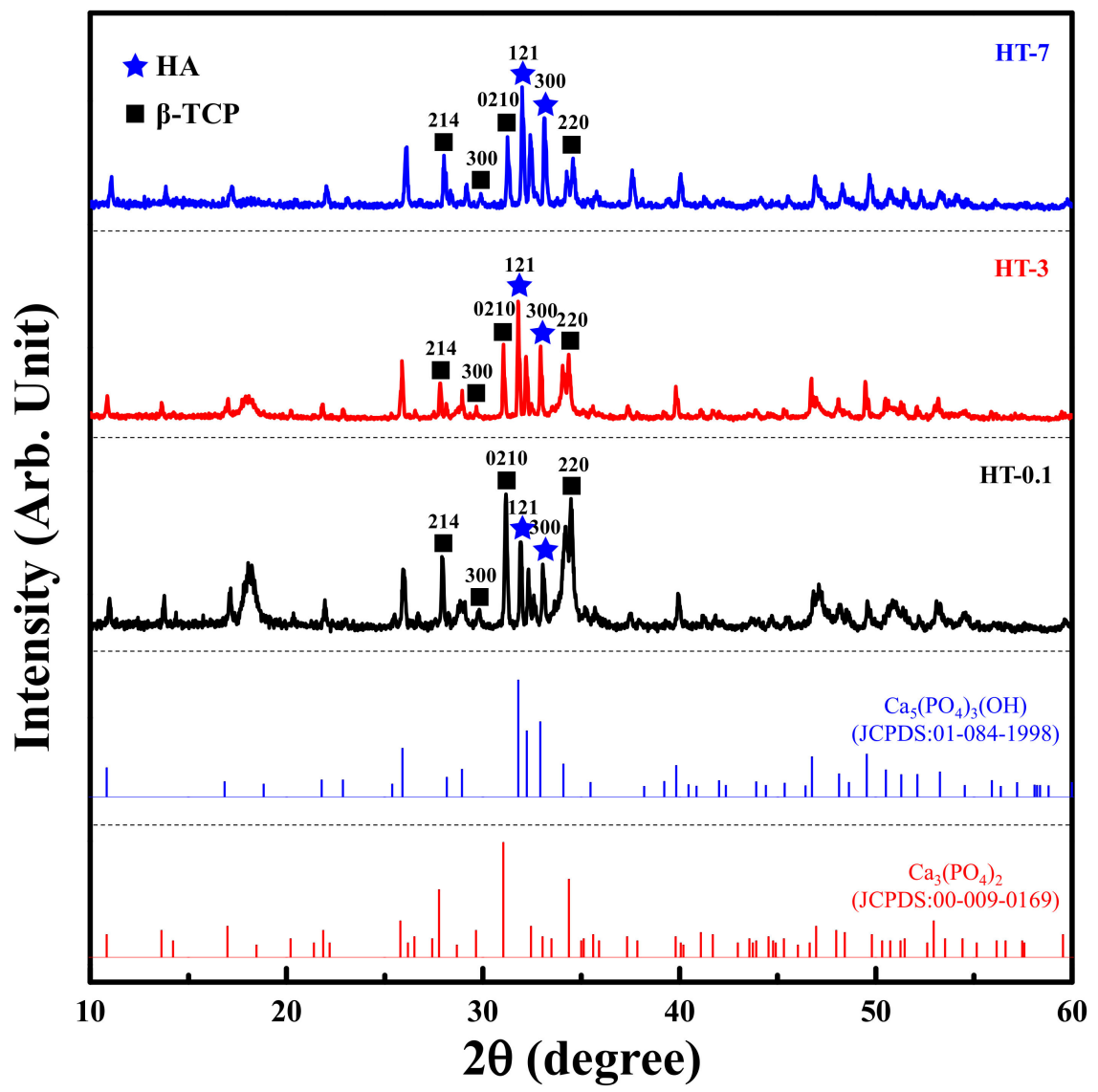

Figure 5. XRD patterns of the samples prepared by the heat treatment of as-prepared coral and DCPA at various durations, including reference spectra for JCPDS 01-084-1988 and 00-009-0169.

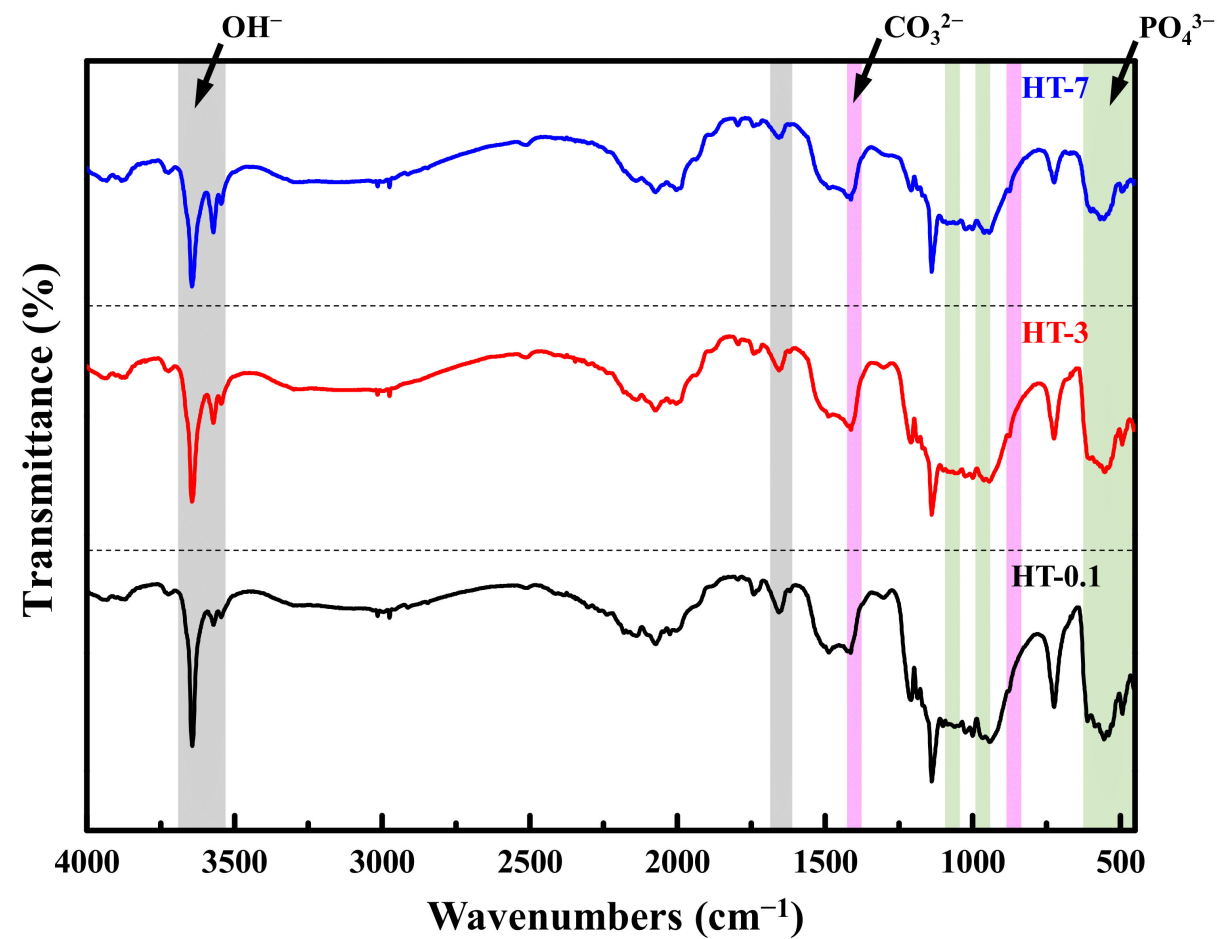

Figure 6. FTIR spectra of the samples prepared by the heat treatment of various durations of asprepared coral and DCPA. Green areas indicate the bond regions of $\mathrm{PO}_{4}^{3-}$ groups; gray areas indicate the bond regions of $\mathrm{OH}^{-}$groups; pink areas indicate the bond regions of $\mathrm{CO}_{3}^{2-}$ groups. 
Figure 7 has the Raman spectra of the samples prepared by calcination of the asprepared coral and DCPA at different durations in the fingerprint region $\left(900-1100 \mathrm{~cm}^{-1}\right)$. All heat-treated samples exhibited the main vibration modes associated with $\mathrm{PO}_{4}^{3-}$ groups: a wideband representing symmetric P-O stretching mode $(v 1)$ located in $930-990 \mathrm{~cm}^{-1}$, and the asymmetric stretching $(v 3)$ was at $1030-1080 \mathrm{~cm}^{-1}$. Some differences were observed in the range between 950 and $980 \mathrm{~cm}^{-1}$. The HT-0.1 sample displayed major peaks at 950, 972, and $1048 \mathrm{~cm}^{-1}$ that could be assigned to the vibrational internal modes of $\mathrm{PO}_{4}^{3-}$ groups of $\beta$-TCP. Some peaks at 964 and $1088 \mathrm{~cm}^{-1}$ were observed in the HT-0.1 sample, indicating the formation of HAp. With the increasing heat-treated time, the peak intensity at $964 \mathrm{~cm}^{-1}$ increased, and that at $1048 \mathrm{~cm}^{-1}$ decreased.

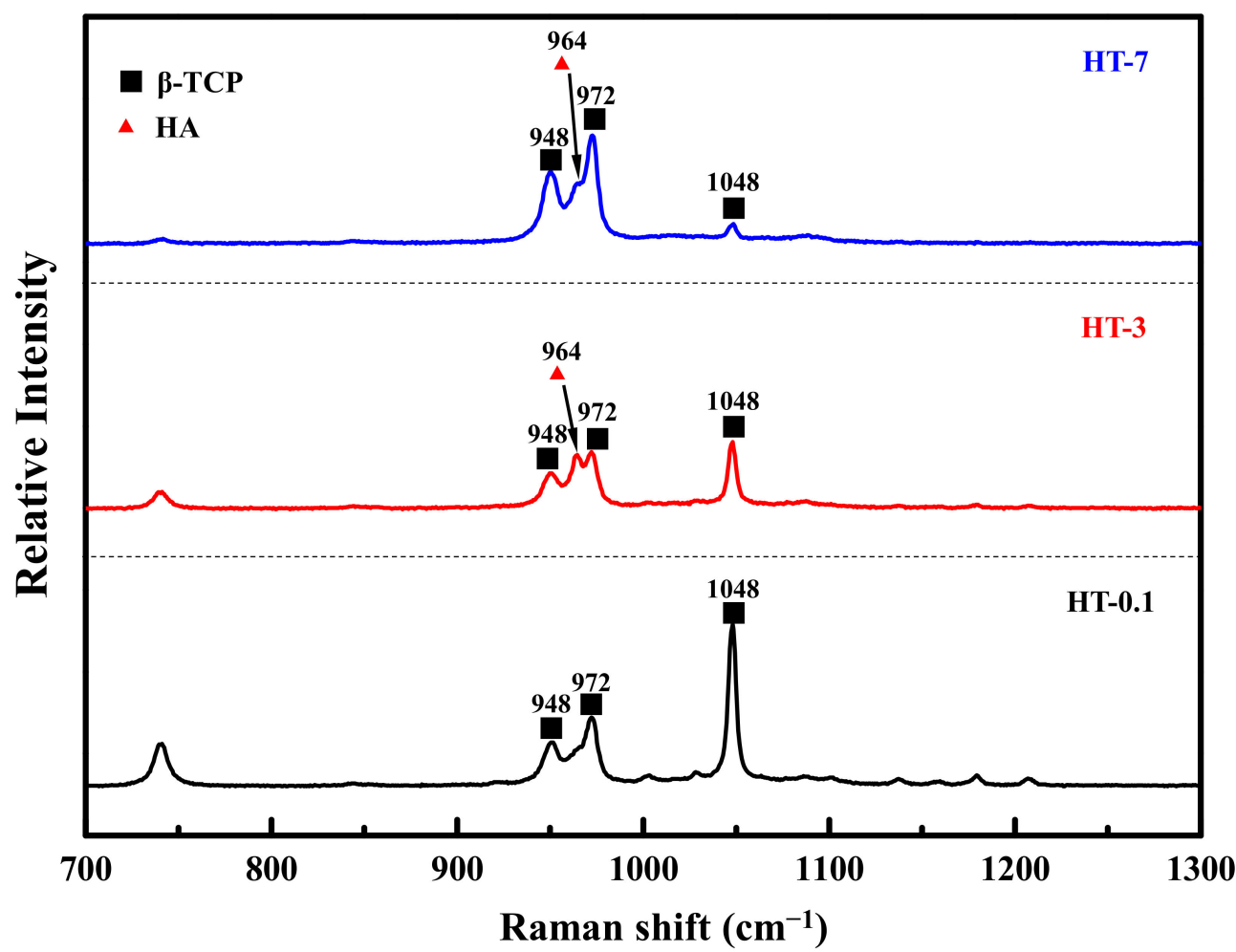

Figure 7. Raman spectra of the investigated samples prepared by the heat treatment of as-prepared coral and DCPA at different durations.

\subsection{In Vitro Cytotoxicity Response}

Based on the above investigations, the HT-3 sample was selected for the study of the heat-treatment conditions discussed in the in vitro cytotoxicity response and in vivo bone defect test. Table 2 has the OD values of cells that were co-cultured with extracts from the HT-3 sample for $24 \mathrm{~h}$. No significant differences in cell viability were observed among the blank, NC, HT-3, and 50\% HT-3 groups, and the cell viabilities were higher than those of the PC group. The cell viabilities of both $50 \%$ and $100 \%$ extracts of the HT-3 sample were higher than 70\%, indicating that the HT-3 sample possessed no acute cytotoxic potential. Figure 8 shows the cell morphology variations of the tested samples. Cells had long spindle shapes with good density in the blank and NC groups (Figure 8a,b), whereas round cells and nearly destruction of the cell layers were observed in the PC group (Figure 8c). The HT-3 group (Figure 8d) had a cell morphology and density similar to the blank and NC groups. 
Table 2. The results of MTT assay for evaluation of cell viability.

\begin{tabular}{cccc}
\hline & OD $_{\mathbf{5 7 0} \mathbf{~ n m}}$ & Viability (\%) & Cell Lysis (\%) \\
\hline Blank & $0.986 \pm 0.002$ & 100 & 0 \\
NC & $0.984 \pm 0.003$ & 100 & 0 \\
PC & $0.098 \pm 0.001$ & 10 & 90 \\
HT-3 & $0.929 \pm 0.035$ & 94 & 6 \\
$50 \%$ HT-3 & $0.963 \pm 0.028$ & 98 & 2 \\
\hline
\end{tabular}

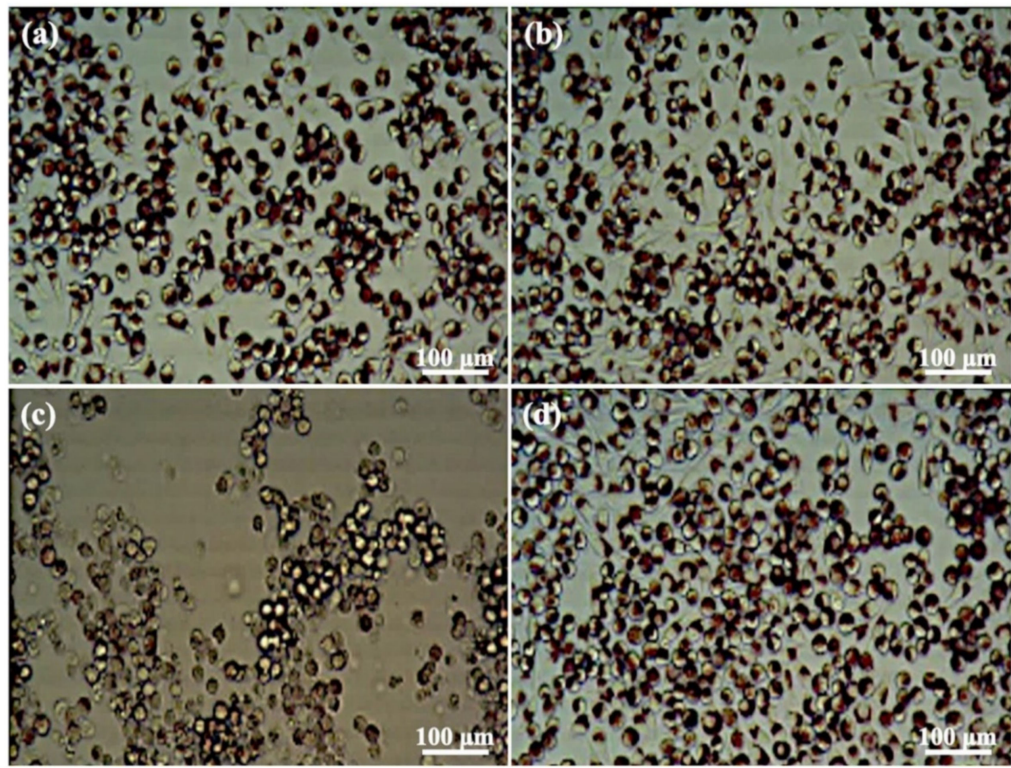

Figure 8. Optical images of the cell morphologies on the investigated samples: (a) blank, (b) negative control, (c) positive control, and (d) HT-3.

\subsection{Bone Tissue Reaction Features}

Figure 9 shows the histological images of the defects. No abnormal behavior or wound infection were found in the two graft materials, the coral samples, or autogenous bone, 4 weeks after the bone graft. Lymphocytes in the HT-3 group were higher than the autogenous bone group, although no significant differences were observed in the overall tissue reaction between the two materials (Table 3). These findings indicate that the HT-3 samples were considered non-responsive to tissues compared to autogenous bone samples after 4 weeks of implantation. The investigated HT-3 sample had no adverse effect on the tissue response and was comparable to that of the autogenous bone sample.

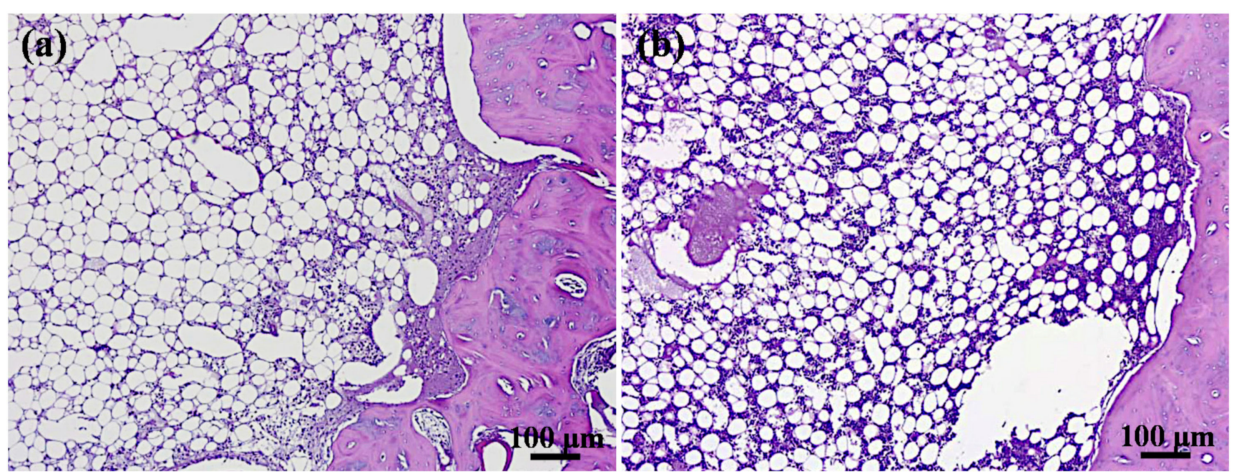

Figure 9. H \& E staining results of the investigated samples after 4 weeks of implantation: (a) control and (b) HT-3. 
Table 3. Histological findings and irritant-ranking scores according to ISO 10993-6: 2016.

\begin{tabular}{cccc}
\hline & HT-3 $(\boldsymbol{n}=\mathbf{1 0})$ & $\begin{array}{c}\text { Autogenous Bone } \\
\text { Group }(\boldsymbol{n = 1 0 )}\end{array}$ & $\boldsymbol{p}$ Value \\
\hline Polymorphonuclea & $1.2 \pm 1.8$ & $0.8 \pm 1.1$ & 0.68 \\
Lymphocytes & $4.4 \pm 0.9$ & $3.6 \pm 0.9$ & 0.20 \\
Plasma cells & 0 & 0 & \\
Macrophages & 0 & 0 & \\
Giant cells & 0 & 0 & \\
Necrosis & 0 & 0 & $>0.05$ \\
Neovascularization & 0 & 0 & 0.67 \\
Fibrosis & $0.6 \pm 0.5$ & $0.6 \pm 0.5$ & \\
Fatty infiltrate & $2.2 \pm 0.5$ & $2.4 \pm 0.9$ & \\
\hline
\end{tabular}

\section{Discussion}

Coral-derived CaP composed of HAp and $\beta$-TCP were obtained after heat treating the mixture of the propagated Scleractinian coral and DCPA at $1100{ }^{\circ} \mathrm{C}$ for as little as $1 \mathrm{~h}$. The DCPA suspension with $\mathrm{NaOH}, \mathrm{NaF}$, or $\mathrm{NaCl}$ was transformed into HAp or TCP after hydrolysis for seven days; however, this process was slow and had complicated pH adjustments [21,22]. Furthermore, traditional porous-forming technologies were hard and relatively rare to realize the complex structures, which were structurally similar to human bone and tooth enamel $[10,11]$. The present study used the propagated Scleractinian coral as a calcium precursor and provided the calcium carbonate microstructure with the inter-connected microporosity.

$\beta$-TCP may be formed at $800{ }^{\circ} \mathrm{C}$ through the dehydration of DCPA to $\beta-\mathrm{Ca}_{2} \mathrm{P}_{2} \mathrm{O}_{7}$ and decomposition of $\mathrm{CaCO}_{3}$ to $\mathrm{CaO}$ [21,24]. Rhee et al. [25] synthesized mixtures of HAp and $\beta$-TCP using mechanochemical treatments. No noticeable changes of the initial two powders, $\mathrm{Ca}_{2} \mathrm{P}_{2} \mathrm{O}_{7}$ and $\mathrm{CaCO}_{3}$, were observed after $8 \mathrm{~h}$ of milling, but the surface area increased, which caused the speculation. Similar results were observed in the present study. A dominant component of the raw material used, the propagated Scleractinian coral, was aragonite $\mathrm{CaCO}_{3}$. The heat treatment for $1 \mathrm{~h}$ resulted in the complete decomposition of the starting materials into only two crystalline phases: HA and $\beta$-TCP. The relative amount of $\beta$-TCP was higher than HAp after $1 \mathrm{~h}$ of heat treatment and decreased with longer heat treatment, implying that $\beta$-TCP was easily formed. The structural similarity between the starting materials and $\beta$-TCP facilitated the transformation from $\mathrm{CaCO}_{3}$ into $\beta$-TCP [16]. In additional, the $\mathrm{Ca} / \mathrm{P}$ ratio of the starting materials also provided favorable conditions for $\beta$-TCP formation [17].

The relatively greater proportion of HAp after increasing heat treatments may result from the instability of $\beta$-TCP [20]. With higher heated temperature, slight hydration and a slight deficit of hydration water in DCPA facilitated to form HAp, as shown in the following reaction [25]:

$$
4 \mathrm{Ca}_{3}\left(\mathrm{PO}_{4}\right)_{4}+2 \mathrm{H}_{2} \mathrm{O} \rightarrow \mathrm{Ca}_{10}\left(\mathrm{PO}_{4}\right)_{6}(\mathrm{OH})_{2}(\text { surface })+2 \mathrm{CaHPO}_{4} .
$$

The diffraction peaks of CaP-based mixtures were overlapped because of the similar chemical structures. Therefore, the vibrational spectroscopies helped characterize vibrations for these materials' amorphous species or crystalline phases [15,29]. The FTIR and Raman spectra results were in good agreement with the XRD findings in the present study. The presence of the Raman (Figure 5) $\mathrm{OH}^{-}$peaks at $3645 \mathrm{~cm}^{-1}$ may result from the adsorbed moisture due to the highly hygroscopic property of phosphates and the appearance of the ambient air atmosphere during heat treatment [24]. The $\mathrm{OH}^{-}$peak decreased with longer heat treatment, suggesting that the conversion of $\beta$-TCP to HA was formed due to the existence of water and the supply of additional hydroxyl groups [25].

The mixture heat-treated for 3 days (HT-3) contained $61 \%$ HAp and $39 \% \beta-\mathrm{TCP}$, and there was no significant difference in HAp/ $\beta$-TCP ratio between HT-3 and HT-7 samples (Table 2). DMSO was used as a positive control because it was cytotoxic. High-density 
polyethylene was used as a negative control to clear the background response of the cells [32]. These results and the MTT assay demonstrated that heat treatment for 3 days was sufficient to generate biphasic $\mathrm{CaP}$ with the stable phase composition and excellent biocompatibility properties [16]. The results of qualitative visual cellular characterization shown in Figure 7 from the cytotoxicity test agreed with those of MTT assay analysis regarding the toxicity of the cells. The cell layer reactivity that resulted from biomaterial extracts can be scored from 0 (no reactivity) to 4 (severe reactivity) [31]. L929 cells exposed to HT-3 showed no reactivity (Grade 1) and were considered cytocompatible.

The pilot study of rabbit femur defects revealed that the HT-3 sample did not induce an irritant response 4 weeks after rabbit femur bone implantation. It had the same biological effect (without adverse effect) as the autogenous bone sample. Therefore, it is believed that the coral-derived biphasic CaPs comprising 61\% HAp and 39\% $\beta$-TCP (i.e., HT-3 sample) not only exhibited good biocompatibility but also possessed the potential to facilitate bone tissue regeneration. More studies should be performed to validate the present findings.

\section{Conclusions}

Biphasic calcium phosphates containing $\beta$-TCP and HAp were synthesized by stirring solutions of propagated coral and dicalcium phosphate anhydrous followed by heat treatments at $1100^{\circ} \mathrm{C}$ for $1 \mathrm{~h}$ to 7 days. The synthesized biphasic CaPs samples displayed no cytotoxic effects. Implantation in bone defects in the rabbit model did not induce locally adverse tissue reactions and had new bone formation. The coral-derived biphasic CaPs with $61 \%$ HAp and $39 \%$-TCP sample are a useful bone graft substitute for bone defect treatment applications.

Author Contributions: Writing-original draft, H.-Y.L. and Y.-J.L.; Funding acquisition, H.-Y.L.; Investigation, Y.-J.L. and H.-H.C.; Conceptualization, H.-H.C. and K.-L.O.; Data curation, Y.-C.C. and Y.-H.O.; Methodology, B.-H.H. and W.-C.L.; Resources, Y.-C.C. and Y.-H.O.; Validation, B.-H.H. and W.-C.L.; Supervision, K.-L.O. and T.S.; Project administration, T.S.; Visualization, T.-S.Y. and P.-W.P.; Writing-review \& editing, T.-S.Y. and P.-W.P. All authors have read and agreed to the published version of the manuscript.

Funding: The authors would like to thank the Fu Jen Catholic University Hospital, Taiwan for financially supporting this research under contract No. PL-202108024-V.

Institutional Review Board Statement: The protocols for animal experiments were reviewed and approved by the Institutional Animal Care and Use Committee for Master Laboratory Co., Ltd. under a project identification code of MSA-202001-20-T08.

Informed Consent Statement: Not applicable.

Data Availability Statement: Data are contained within the article.

Conflicts of Interest: The authors declare no conflict of interest.

\section{References}

1. Shi, Y.; Pan, T.; Zhu, W.; Yan, C.; Xia, Z. Artificial bone scaffolds of coral imitation prepared by selective laser sintering. J. Mech. Behav. Biomed. Mater. 2020, 104, 103664. [CrossRef] [PubMed]

2. Matuda, Y.; Okamura, T.; Tabata, H.; Yasui, K.; Tatsumura, M.; Kobayashi, N.; Nishikawa, T.; Hashimoto, Y. Periodontal Regeneration Using Cultured Coral Scaffolds in Class II Furcation Defects in Dogs. J. Hard Tissue Biol. 2019, 28, 329-334. [CrossRef]

3. Takeuchi, A.; Tsuge, T.; Kikuchi, M. Preparation of porous $\beta$-tricalcium phosphate using starfish-derived calcium carbonate as a precursor. Ceram. Int. 2016, 42, 15376-15382. [CrossRef]

4. Chou, J.; Hao, J.; Ben-Nissan, B.; Milthorpe, B.; Otsuka, M. Coral exoskeletons as a precursor material for the development of a calcium phosphate drug delivery system for bone tissue engineering. Biol. Pharm. Bull. 2013, 36, 1662-1665. [CrossRef]

5. He, F.; Zhang, J.; Yang, F.; Zhu, J.; Tian, X.; Chen, X. In vitro degradation and cell response of calcium carbonate composite ceramic in comparison with other synthetic bone substitute materials. Mater. Sci. Eng. C 2015, 50, 257-265. [CrossRef]

6. Neto, A.S.; Ferreira, J.M.F. Synthetic and Marine-Derived Porous Scaffolds for Bone Tissue Engineering. Materials 2018, 11, 1702. [CrossRef] 
7. Cui, W.; Song, Q.; Su, H.; Yang, Z.; Yang, R.; Li, N.; Zhang, X. Synergistic effects of Mg-substitution and particle size of chicken eggshells on hydrothermal synthesis of biphasic calcium phosphate nanocrystals. J. Mater. Sci. Technol. 2020, 36, 27-36. [CrossRef]

8. Eliaz, N.; Metoki, N. Calcium phosphate bioceramics: A review of their history, structure, properties, coating technologies and biomedical applications. Materials 2017, 10, 334. [CrossRef]

9. Bohner, M.; Santoni, B.L.G.; Döbelin, N. $\beta$-tricalcium phosphate for bone substitution: Synthesis and properties. Acta Biomater. 2020, 113, 23-41. [CrossRef]

10. Roy, D.M.; Linnehan, S.K. Hydroxyapatite formed from coral skeletal carbonate by hydrothermal exchange. Nature 1974, 247, 220-222. [CrossRef]

11. Jinawath, S.; Polchai, D.; Yoshimura, M. Low-temperature, hydrothermal transformation of aragonite to hydroxyapatite. Mater Sci. Eng. C 2002, 22, 35-39. [CrossRef]

12. Rosa Cegla, R.-N.; Macha, I.J.; Ben-Nissan, B.; Grossin, D.; Heness, G.; Chung, R.-J. Comparative study of conversion of coral with ammonium dihydrogen phosphate and orthophosphoric acid to produce calcium phosphates. J. Aust. Ceram. Soc. 2014, 50, 154-161.

13. Nandi, S.K.; Kundu, B.; Mukherjee, J.; Mahato, A.; Datta, S.; Balla, V.K. Converted marine coral hydroxyapatite implants with growth factors: In vivo bone regeneration. Mater. Sci. Eng. C 2015, 49, 816-823. [CrossRef]

14. Karacan, I.; Ben-Nissan, B.; Sinutok, S. Marine-Based Calcium Phosphates from Hard Coral and Calcified Algae for Biomedical Applications. In Marine-Derived Biomaterials for Tissue Engineering Applications; Springer: Berlin/Heidelberg, Germany, 2019; pp. 137-153.

15. Vallet-Regi, M.; González-Calbet, J.M. Calcium phosphates as substitution of bone tissues. Prog. Solid State Chem. 2004, 32, 1-31. [CrossRef]

16. Webler, G.; Zapata, M.; Agra, L.; Barreto, E.; Silva, A.; Hickmann, J.; Fonseca, E. Characterization and evaluation of cytotoxicity of biphasic calcium phosphate synthesized by a solid state reaction route. Curr. Appl. Phys. 2014, 14, 876-880. [CrossRef]

17. Mirjalili, F.; Bagheshahi, S.; Aghaee, M. Synthesis and characterization of $\beta$-TCP/HA nanocomposite: Morphology and microstructure. J. Thermoplast. Compos. Mater. 2020, 33, 1292-1313. [CrossRef]

18. Roopavath, U.K.; Sah, M.K.; Panigrahi, B.B.; Rath, S.N. Mechanochemically synthesized phase stable and biocompatible $\beta$ tricalcium phosphate from avian eggshell for the development of tissue ingrowth system. Ceram. Int. 2019, 45, 12910-12919. [CrossRef]

19. Zhang, L.; Zhang, C.; Zhang, R.; Jiang, D.; Zhu, Q.; Wang, S. Extraction and characterization of HA/ $\beta$-TCP biphasic calcium phosphate from marine fish. Mater. Lett. 2019, 236, 680-682. [CrossRef]

20. Ho, W.-F.; Hsu, H.-C.; Hsu, S.-K.; Hung, C.-W.; Wu, S.-C. Calcium phosphate bioceramics synthesized from eggshell powders through a solid state reaction. Ceram. Int. 2013, 39, 6467-6473. [CrossRef]

21. Laonapakul, T.; Sutthi, R.; Chaikool, P.; Talangkun, S.; Boonma, A.; Chindaprasirt, P. Calcium phosphate powders synthesized from $\mathrm{CaCO}_{3}$ and $\mathrm{CaO}$ of natural origin using mechanical activation in different media combined with solid-state interaction Mater. Sci. Eng. C 2021, 118, 111333. [CrossRef]

22. Guo, X.; Yan, H.; Zhao, S.; Li, Z.; Li, Y.; Liang, X. Effect of calcining temperature on particle size of hydroxyapatite synthesized by solid-state reaction at room temperature. Adv. Powder Technol. 2013, 24, 1034-1038. [CrossRef]

23. Hou, P.-J.; Lee, C.-Y.; Ou, K.-L.; Lan, W.-C.; Chuo, Y.-C.; Lin, H.-Y.; Chao, H.-W.; Huang, B.-H.; Saito, T.; Tsai, H.-Y. Calcium release from different toothpastes after the incorporation of tricalcium phosphate and amorphous calcium phosphate. Appl. Sci. 2021, 11, 1848. [CrossRef]

24. Choi, D.; Kumta, P.N. Mechano-chemical synthesis and characterization of nanostructured $\beta$-TCP powder. Mater. Sci. Eng. C 2007, 27, 377-381. [CrossRef]

25. Rhee, S.-H. Synthesis of hydroxyapatite via mechanochemical treatment. Biomaterials 2002, 23, 1147-1152. [CrossRef]

26. Barton, J.A.; Willis, B.L.; Hutson, K.S. Coral propagation: A review of techniques for ornamental trade and reef restoration. Rev. Aquac. 2017, 9, 238-256. [CrossRef]

27. Liu, S.; Chen, J.; Chen, T.; Zeng, Y. Fabrication of trabecular-like beta-tricalcium phosphate biomimetic scaffolds for bone tissue engineering. Ceram. Int. 2021, 47, 13187-13198. [CrossRef]

28. Ferreira, J.; Kannan, S. Phase transition mechanisms involved in the formation of structurally stable $\beta-\mathrm{Ca}_{3}\left(\mathrm{PO}_{4}\right) 2-\alpha-\mathrm{Al}_{2} \mathrm{O}_{3}$ composites. J. Eur. Ceram. Soc. 2017, 37, 2953-2963.

29. Sinusaite, L.; Grigoraviciute-Puroniene, I.; Popov, A.; Ishikawa, K.; Kareiva, A.; Zarkov, A. Controllable synthesis of tricalcium phosphate (TCP) polymorphs by wet precipitation: Effect of washing procedure. Ceram. Int. 2019, 45, 12423-12428. [CrossRef]

30. Aguiar, H.; Chiussi, S.; López-Álvarez, M.; González, P.; Serra, J. Structural characterization of bioceramics and mineralized tissues based on Raman and XRD techniques. Ceram. Int. 2018, 44, 495-504. [CrossRef]

31. Narayan, R. Encyclopedia of Biomedical Engineering; Elsevier: Amsterdam, The Netherlands, 2018.

32. Wallin, R.F.; Arscott, E. A practical guide to ISO 10993-5: Cytotoxicity. Med. Device Diagn. Ind. 1998, $20,96-98$. 